\title{
Papillary thyroid carcinoma in children: 33 years of experience of a single institution in Serbia
}

\section{Authors:}

Marko Butal', Ivan Markovic 1,2 , Milovan Matovic ${ }^{3,4}$, Nada Santracl, Igor Djurisicl', Zorka Milovanovic 5 , Gordana Pupic ${ }^{5}$, Radan Dzodic 1,2

${ }^{1}$ Institute for Oncology and Radiology of Serbia, Surgical Oncology Clinic, Belgrade, Serbia

2 University of Belgrade, School of Medicine, Belgrade, Serbia

${ }^{3}$ Clinical Center of Kragujevac, Department of Nuclear Medicine, Kragujevac, Serbia

${ }^{4}$ University of Kragujevac, Medical School, Kragujevac, Serbia

${ }^{5}$ Institute for Oncology and Radiology of Serbia, Department of Pathology, Pasterova 14, Belgrade, Serbia

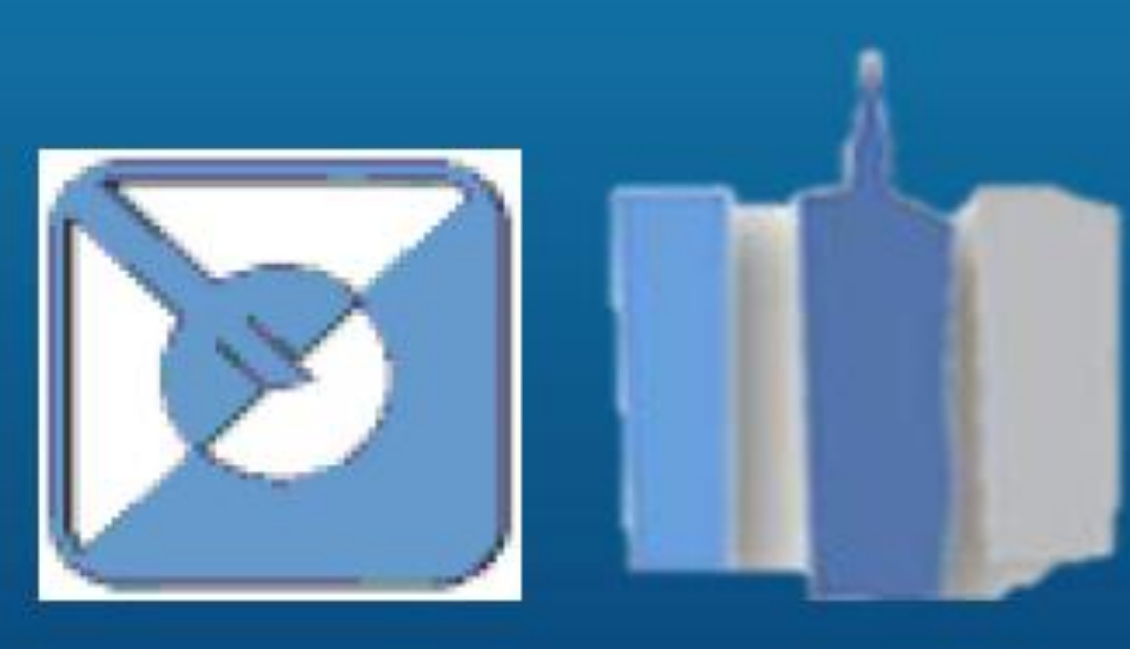

\section{INTRODUCTION}

Well differentiated thyroid carcinoma in children is rare [1], but it shows aggressive behaviour. Gross lymph node metastases and distant metastases are common on first clinical presentation [2].

The aim of this study was to analyze the clinical features, effectiveness of surgical approach, radioactive iodine (RAI) therapy, thyroxin suppressive-substitutional treatment and long-term outcome of 24 patients under or equal to 16 years of age, with welldifferentiated thyroid carcinoma surgically treated in our institution.

\section{MATERIALS AND METHODS}

During 33 years (1981-2014) at the Institute for oncology and radiology of Serbia 24 children were operated due to papillary thyroid carcinoma. Mean age was 12.6 (range 716) years. At the time of diagnosis, $12.5 \%$ patients had lung metastases. Total thyroidectomy or completion of thyroidectomy was performed in all cases, followed with central neck dissection and frozen section examination of the jugulo-carotid compartments. Median follow-up was 10.1 (range $2.0-29.4$ ) years.

\section{RESULTS}

All patients had papillary thyroid carcinoma. pTla tumors were found in $12.5 \%$, pTlb in $25 \%$, pT2 in $20.83 \%$, pT3 in $25 \%$ and pT4 in $16.67 \%$. Multifocal tumors were found in $79.17 \%$ and capsular invasion in $83.33 \%$. Lymphonodal metastases in either central or lateral neck compartments were found in $75 \%$ of patients. Median DFI has not been reached and overall survival rate was $100 \%$.

\section{CONCLUSION}

Papillary thyroid carcinoma in children is characterized with high rate of loco-regional aggressiveness, multifocality, capsular invasion, lymph node metastases and distant metastases at the time of diagnosis. Extensive surgical approach should be performed in both primary and recurrent disease in young patients with well differentiated thyroid carcinoma in order to achieve loco-regional disease control and long disease free survival.

\section{REFERENCES}

1. Halac I, Zimmerman D. Thyroid nodules and cancers in children. Endocrinol Metab Clin North Am 2005; 34: 725-744

2. Welch Dinauer CA, Tuttle RM, Robie DK, McClellan DR, Svec RL, et al. Clinical features associated with metastasis and recurrence of differentiated thyroid cancer in children adolescents and young adults. Clin Endocrinol (Oxf) 1998; 49: 619-628.

Thyroid cancer 